\title{
Hepatitis E Virus (HEV) Seroprevalence in the general population of the Republic of Korea in 2007-2009: a nationwide cross-sectional study
}

Youngsil Yoon ${ }^{1}$, Hye Sook Jeong ${ }^{1}$, Haesun Yun ${ }^{1,4}$, Hyeokjin Lee ${ }^{1}$, Yoo-Sung Hwang ${ }^{2}$, Bohyun Park ${ }^{2}$, Chae Jin Lee ${ }^{3,5}$, Sangwon Lee ${ }^{1}$ and Ji-Yeon Hyeon ${ }^{1 *}$

\begin{abstract}
Background: Hepatitis E virus (HEV) is an emerging pathogen associated with endemic and acute viral hepatitis. In this study, we investigate the HEV seroprevalence and putative risk factors by a nationwide cross-sectional study in the Republic of Korea.

Methods: The prevalence of anti-HEV antibody was investigated in 2,450 serum samples collected in fourth Korea National Health and Nutrition Examination Survey. In addition, epidemiological information on possible risk factors including gender, age, education, occupation, and residence location for exposure to HEV was obtained.

Results: The frequency of anti-ElA reactive sample was 5.9\% (144/2450). The individuals in groups with male, older age, low education level and living in rural or coastal regions had high seroprevalence estimates $(P \leq 0.001)$. In addition, seroprevalence was significantly higher among individuals with self-identified skilled agricultural, forestry, and fishery workers $(31.3 \%, P<0.001)$.

Conclusions: This study provides valuable data that could be used to investigate associations of HEV seroprevalence and putative risk factors by a nationwide cross-sectional study. The high HEV seroprevalence of skilled agricultural, forestry, and fishery workers and individuals lived in coastal and rural area indicated that zoonotic transmission is an important risk factor for HEV infection in the republic of Korea. Further studies that include detailed and continuous nationwide surveys are required to identify unrecognized risk factors and to monitor the HEV infection prevalence.
\end{abstract}

Keywords: Hepatitis E virus, Seroprevalence, National survey, Republic of Korea

\section{Background}

Hepatitis E virus (HEV) is a member of the genus Hepevirus, family Hepeviridae, and is a non-enveloped virus with a single-stranded, positive-sense RNA genome of approximately $7.5 \mathrm{~kb}$ [1]. It usually causes mild disease, inflammation of the liver, and the overall mortality rate of HEV-infected individuals is approximately 1\% [2]. However, the mortality rate is significantly higher $(20 \sim 30 \%)$ among HEV-infected pregnant women in endemic countries such as India and Pakistan [3,4]. The epidemiology of HEV infection can be divided into two patterns [5]. The

\footnotetext{
* Correspondence: jyhyeon1205@gmail.com

'Division of Vaccine Research, Korea National Institute of Health, Korea Centers for Disease Control and Prevention, Osong-eup, CheongJu, Chungcheongbuk-do 363-951, Republic of Korea

Full list of author information is available at the end of the article
}

first is an outbreak pattern in areas of high endemicity such as Central and Southeast Asia, Middle East, North Africa, and India [6,7]. This pattern usually has been associated with fecal-to-oral transmission of HEV genotype 1 and $2[4,8]$. HEV infection in industrialized countries is generally associated with travel to these endemic areas. The second is a sporadic pattern that is seen in worldwide and occurs via zoonotic transmission and foodborne transmission such as consumption of raw meat obtained from infected swine, deer, or boar [9-11]. In previous studies, anti-HEV antibodies were detected in pigs, cattle, rodents, and monkeys, and zoonotic transmission from pigs has been reported [7,12]. In addition, HEV genotype 3 and 4 are detected in swine, wild boar, deer, and rabbit 
and is associated with autochthonous infection in industrialized countries $[4,13]$ In previous studies, the overall prevalence of anti-HEV antibodies in human and animals were about $20 \%$ in human, $31.5 \%$ in dogs, $14.8 \%$ in swine, $10.1 \%$ in cats, and $3.5 \%$ in cattle in the Republic of Korea [14-16]. In addition, HEV genotype 3 or genotype 4 were isolated from human, swine, wild boar, and oyster in the Republic of Korea [12,14,15,17]. Although there is an increased research interest in HEV, the exact routes of transmission remain unclear and are merely based on case reports. The several cases by zoonotic (foodborne) transmission and blood transfusion were reported, but these are unlikely to explain all HEV cases $[7,9]$. Thus, the study about the transmission route and risk profile of $\mathrm{HEV}$ infection would be needed to better understand the epidemiological profile of HEV.

The aim of this study was to investigate associations of HEV seroprevalence and putative risk factors by a nationwide cross-sectional study.

\section{Methods \\ Study population}

A total of 2,450 individuals were randomly selected from 7,576 participants of the fourth Korea National Health and Nutrition Examination Survey (KNHANES IV) that was conducted between 2007 and 2009.

KNHANES is nationally representative cross-sectional survey and has been conducted by the Korea Centers for Disease Control and Prevention (KCDC) based on the National Health Promotion Act [18]. It used a rolling sampling survey design that involved a stratified, multi-stage, clustered probability sampling. The details about KNHANES IV were reported in Kweon et al's study [18].

The participants were grouped on the basis of their age into 10-year age groupings and the age of the survey participants ranged between 10-55 years. Residence with a population of $>200,000$ was defined as urban area, and all others were defined as rural area. Region was categorized to coastal and inland area by Coastal Management Act of Korea Ministry of Land, Transport, and Maritime affairs. The individuals of coastal area group resided within $1 \mathrm{~km}$ from coastline, and the others not defined as coastal area was defined as inland area group. The anti-HEV IgG analysis was performed with the selected sample of 2,450 individuals on the basis of their residential area in each age stratum.

Serum samples were stored at $-80^{\circ} \mathrm{C}$ until required for analysis at the National Biobank of Korea (Seoul, Korea). Informed consent was provided by all of the participants in the KNHANES IV study, and the study was approved by the Institutional Review Board of the Neodin Medical Institute (Seoul) prior to initiation.

\section{Enzyme-linked immunosorbent assay (ELISA) for anti-HEV IgG}

We estimated the presence of anti-HEV immunoglobulin G (IgG) by using a commercial HEV IgG ELISA kit according to the manufacturer's instructions (Beijing Wantai Biological Pharmacy Enterprise, Beijing, China), and the results were presented as frequency of anti-HEV reactivity. This kit was produced with a recombinant peptide corresponding to amino-acid residues 396 to 606 of the major structural protein of the HEV [19]. Serum samples with absorbance values greater than or equal to the cut-off value ( 0.16 in this study) were considered positive. ELISA tests were performed duplicate in all samples.

\section{Statistical analysis}

The participant demographic and socioeconomic status including gender, age, educational achievements, occupation, and region were derived from their study questionnaire. The association of frequency of anti-HEV EIA reactivity and environmental risk factors was assessed by using logistic regression and chi-squared tests. Differences were considered to be statistically significant at $P<0.05$. Data analyses were performed by using the statistical package SAS (version 9.1, SAS Institute, Cary, NC, USA).

\section{Ethical approval}

This study was approved by the Institutional Review Board of the Neodin Medical Institute (2011-01).

\section{Results}

The overall frequency of anti-HEV IgG EIA reactivity was found to be $5.9 \%(144 / 2,450)$. Furthermore, $7.8 \%$ (77/994) male participants and 4.6\% (67/1,456) female participants were seropositive $(P=0.0001)$ (Table 1$)$. Data analysis using age-group stratification indicated a significant increase in frequency of anti-HEV IgG EIA reactivity with increasing age $(P<0.0001)$. The frequency of anti-HEV IgG EIA reactivity of individuals in their $20 \mathrm{~s} 30 \mathrm{~s}, 40 \mathrm{~s}$, and $50 \mathrm{~s}$ were $1.2 \%$ (9/521), 2.4\% (13/553), $12.0 \%(67 / 557)$, and $20.9 \%$ (57/273), respectively with increasing odd ratios (ORs) from 6.3 to 143.8 (Table 1).

To better understand the epidemiological profile and risk factor of $\mathrm{HEV}$ infection, the association of seropositive rates and educational level, occupation, and residence location were assessed. Groups with educational levels of elementary school or below, middle school graduate, high school graduate and university graduate had seropositive individual rates of $20.5 \%$ (27/132), $15.1 \%(23 / 152), 9.0 \%(56 / 621)$ and $6.6 \%$ (31/473), respectively $(P<0.0001)$ (Table 2$)$.

The skilled agricultural, forestry, and fishery workers showed the highest frequency of anti-HEV IgG EIA reactivity $(31.3 \%, 15 / 48)$ and associated with significantly 
Table 1 Frequency of anti-HEV IgG EIA reactivity associated with gender and age among participants in the Korea National Health and Nutrition Examination Survey, 2007-2009

\begin{tabular}{|c|c|c|c|c|}
\hline Variable & Tested $(n=2,450)$ & Positive for anti-HEV, N (\%) & $P$ value* & OR $(95 \% \mathrm{Cl})$ \\
\hline Overall prevalence & 2,450 & $144(5.9)$ & - & \\
\hline \multicolumn{5}{|l|}{ Sex } \\
\hline Male & 994 & $77(7.8)$ & 0.001 & 1.0 \\
\hline Female & 1,456 & $67(4.6)$ & & $0.6(0.4-0.8)$ \\
\hline \multicolumn{5}{|l|}{ Age (years) } \\
\hline $10-19$ & 546 & $1(0.2)$ & $<.0001$ & 1.0 \\
\hline $20-29$ & 521 & $6(1.2)$ & & $6.3(0.8-52.9)$ \\
\hline $30-39$ & 553 & $13(2.4)$ & & $13.1(1.7-100.6)$ \\
\hline $40-49$ & 557 & $67(12.0)$ & & $74.5(10.3-538.5)$ \\
\hline $50-55$ & 273 & $57(20.9)$ & & $143.8(19.8->999.9)$ \\
\hline
\end{tabular}

*If $P<0.05$, the differences of seroprevalence among compared groups are statistically significant.

high odd of HEV seropositivity (OR, 6.6 [95\% CI, 3.114.2]) (Table 2). The seropositive rates for elementary workers also showed high frequency of anti-HEV IgG EIA reactivity (13.3\%, 20/151) (OR, 2.2 [95\% CI, 1.1-4.3]). However, the frequency of anti-HEV IgG EIA reactivity in equipment, machine operators and manufacturing workers $(8.7 \%, 20 / 230)$, service provider and seller $(7.3 \%$, 26/357), managers and professionals (6.4\%, 19/295), and clerks $(6.0 \%, 14 / 234)$ were lower than other occupation groups (Table 2).

The incidence of HEV seropositive individuals was the highest in Jeju-do $(15.0 \%, 16 / 107)$, followed by Jeollabuk-do (12.5\%, 11/88), Jeollanam-do (9.4\%, 20/212), and Chungcheongnam-do (9.3\%, 11/118; Figure 1). The coastal/inland, urban/rural residence classification showed differences in frequency of anti-HEV IgG EIA reactivity

Table 2 Frequency of anti-HEV IgG EIA reactivity associated with educational level, occupation and region of the participants in the Korea National Health and Nutrition Examination Survey, 2007-2009

\begin{tabular}{|c|c|c|c|c|}
\hline Variable & Tested $^{\mathrm{a}}$ & Positive for anti-HEV, N (\%) & $P$ value $^{\mathrm{b}}$ & OR $(95 \% \mathrm{Cl})$ \\
\hline \multicolumn{5}{|l|}{ Educational level $^{c}$} \\
\hline Elementary school or below & 132 & $27(20.5)$ & $<.0001$ & 1.0 \\
\hline Middle school graduate & 152 & $23(15.1)$ & & $0.7(0.4-1.3)$ \\
\hline High school graduate & 621 & $56(9.0)$ & & $0.4(0.2-0.6)$ \\
\hline University graduate & 473 & $31(6.6)$ & & $0.3(0.2-0.5)$ \\
\hline \multicolumn{5}{|l|}{ Occupation } \\
\hline Managers, Professionals & 295 & $19(6.4)$ & $<.0001$ & 1.0 \\
\hline Clerks & 234 & $14(6.0)$ & & $0.9(0.5-1.9)$ \\
\hline Service provider and Seller & 357 & $26(7.3)$ & & $1.1(0.6-2.1)$ \\
\hline Skilled Agricultural, Forestry and Fishery Workers & 48 & $15(31.3)$ & & $6.6(3.1-14.2)$ \\
\hline Equipment, Machine Operators and Manufacturing Workers & 230 & $20(8.7)$ & & $1.4(0.7-2.7)$ \\
\hline Elementary Workers & 151 & $20(13.3)$ & & $2.2(1.1-4.3)$ \\
\hline Unemployed (housewife, student, etc.) & 819 & $29(3.5)$ & & $0.5(0.3-0.9)$ \\
\hline \multicolumn{5}{|l|}{ Residence } \\
\hline Urban area & 1,937 & $90(4.7)$ & $<.0001$ & 1.0 \\
\hline Rural area & 513 & $54(10.5)$ & & $0.4(0.3-0.6)$ \\
\hline \multicolumn{5}{|l|}{ Region of residence } \\
\hline Coastal area & 1,064 & $90(8.5)$ & $<.0001$ & 1.0 \\
\hline Inland area & 1,386 & $54(3.9)$ & & $2.4(1.7-3.4)$ \\
\hline
\end{tabular}

${ }^{a}$ The total no. of participants shown is $<2,450$, owing to deficient reporting.

${ }^{b}$ If $P<0.05$, the differences of seroprevalence among compared groups are statistically significant.

${ }^{\mathrm{C}}$ The seovprevalence of individuals over the age of 10 years old were used for this data. 


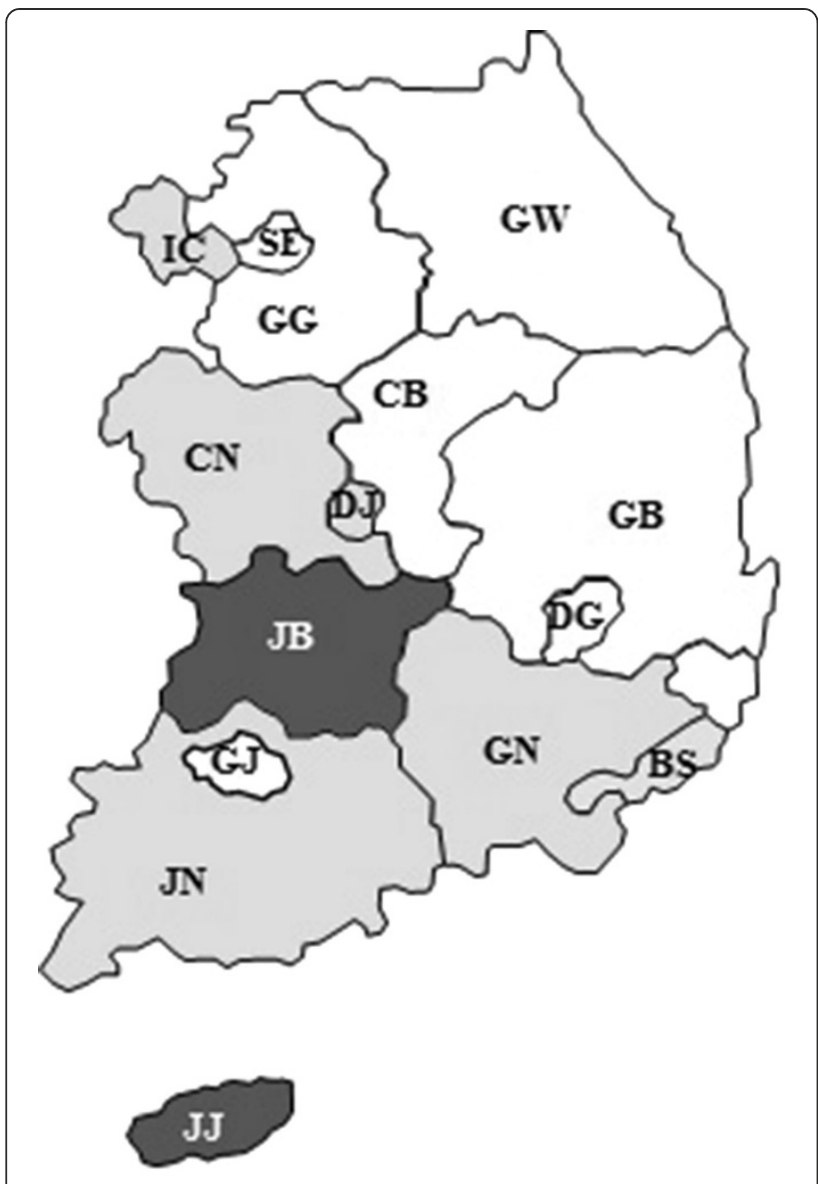

\section{Anti-hepatitis E virus (anti-HEV) IgG EIA reactivity}

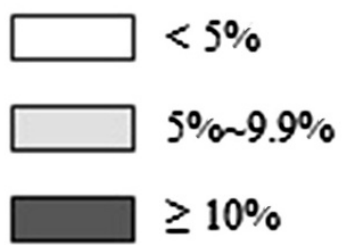

Figure 1 Map of Korea showing a frequency of anti-hepatitis $E$ virus (anti-HEV) Ig G EIA reactivity in the 16 regions of the Korea National Health and Nutrition Examination Survey, 20072009. GW, Gangwon-do; GG, Gyeonggi-do; GN, Gyeongsangnam-do; GB, Gyeongsangbuk-do; GJ, Gwangju; DG, Daegu; DJ, Daejeon; BS, Busan; SE, Seoul; US, Ulsan; IC, Incheon; JN, Jeollanam-do; JB, Jeollabuk-do; JJ, Jeju-do; CN, Chungchengnam-do; CB, Chungchengbuk-do.

based on the area of residence. The coastal areas demonstrated a significantly higher frequency of anti-HEV IgG EIA reactivity $(8.5 \%, 90 / 1,064)$ than the inland areas $(3.9 \%$, 54/1,386; Table 2). The rural areas had a significantly higher frequency of anti-HEV IgG EIA reactivity (10.5\%, $54 / 513)$ than that of the urban areas $(4.7 \%, 90 / 1,937$; Table 2).

\section{Discussion and conclusions}

On the basis of the testing of 2,450 KNHANES IV study participants, the overall frequency of anti-HEV IgG EIA reactivity in the general population of the Republic of Korea was estimated to be 5.9\% between 2007 and 2009.

The anti-HEV IgG EIA reactivity of this study was the lowest compared to other studies in Korea, $11.9 \%$ in 2003 and 2004 [12], 9.41\% in a previous KNHANES III study between 2004 and 2006 [11], and $14.3 \sim 23.1 \%$ in the group over the age of 20 years old in 2006 [16]. In addition, it was lower than that of Taiwan (12.9\%) and [20] but was higher than Japan (5.3\%), Italy (2.6\%), Spain (2.17\%), and Netherland (1.9\%) [4,21-23]. However, the seroprevalence data in these seroepidemiological studies should be compared with consideration of sensitivity and specificity of assays they used. For example, 28-50\% of the anti-HEV EIA reactive samples were negative in the confirmatory test, recombinant immunoblot (RIB) $[4,23,24]$. In addition, among the anti-HEV EIA assay, Wantai assay has been reported to have greater sensitivity than Genelabs assay in previous studies $[16,25]$ and seropositivity of anti-HEV IgG was $14.3 \%$ in the Genelabs assay and $23.1 \%$ in the Wantai assay in Park et al's study [16]. Therefore, we presented the seroprevalence data as frequency of anti-HEV reactivity rather than as anti-HEV prevalence, because we estimated anti-HEV seroprevalence using one assay, Wantai assay.

The present study demonstrated that older age, being male, low education level, working in agricultural, forestry, and fishery, and living in the costal and rural region were independently associated with risk of a past or recent exposure to HEV. The seroprevalence in men was higher than that in women. This was also observed by other studies, suggesting that men are at higher risk of developing disease following exposure compared to women $[4,26]$. In addition, the strong association between age and HEV seroprevalence was revealed in our study and several previous studies $[4,11,27-30]$, and it most likely reflects cumulative lifetime contact frequency to HEV. The analyses in this study showed that educational level was inversely related to the prevalence of anti-HEV antibodies. However, previous studies have indicated that there was no also no difference in anti-HEV seroprevalence according to educational status $[31,32]$. The geographic variations in HEV seroprevalence in this study was appear to be influenced by the distribution of occupation in each region of Korea. The high seroprevalence regions had higher proportion of skilled agricultural, forestry, and fishery workers and elementary workers, Jeju-do (17.4\%), Jeollabuk-do (17.1\%), Jeollanam-do (17.9\%), and Chungcheongnam-do (18.4\%) than other regions such as Gyeonggi-do (4.9\%) and Gyeongsangnam-do (6.1\%) (data not shown).

Most cases of HEV infection in non-endemic countries have been associated with travel to HEV endemic 
regions, but sporadic autochthonous hepatitis E occur by zoonotic transmission $[7,12]$. The results of this study supported the hypothesis that zoonotic transmission is an important risk factor for HEV infection in the republic of Korea. First, skilled agricultural, forestry, and fishery workers had the highest risk of being seropositive for HEV compared with other occupation group in our study. Similarly, professionals such as veterinarians and famers that are in frequent contact with animals, as well as people who frequently consume raw animal products, have a high prevalence of anti-HEV antibodies in other studies $[9,10,12]$.

Second, previous epidemiological studies have identified consumption of HEV contaminated raw shellfish and oysters as an important risk factor for HEV infection [33,34]. A recent study conducted in the republic of Korea showed that HEV genotype 3 that closely resembles a Korean strain of swine HEV was present in oysters and that the consumption of contaminated shellfish caused sporadic acute hepatitis E cases [15,35]. The higher seroprevalence of coastal and rural areas in this study could be attributed to the more frequent contact with animals and raw shellfish. However, because the risk factors for HEV infection are not well defined, data for risk factor assessment could not be collected during the KNHANES IV study, resulting in our inability to conclusively examine the route of transmission or the extent of zoonotic HEV infections and the role of consumption of uncooked or undercooked meats HEV infections in the republic of Korea.

Overall, the seroprevalence of anti-HEV antibodies was evaluated by conducting a national survey and the association of serum anti-HEV antibodies with subject age, gender, region of residency, education level, and occupation was evaluated. Although HEV is non-endemic in the republic of Korea, the prevalence of anti-HEV antibodies in the Korean population was relatively higher than that of countries with non-endemic HEV. In addition, occupational exposure to infected animals and consuming contaminated food play a significant role in autochthonous hepatitis $\mathrm{E}$ in the republic of Korea, and several other identified potential associations, like older age and gender, consistent with findings in studies. Therefore, this study provides information that may be used for HEV risk factor assessment to prevent and reduce HEV infection in this country. Further studies that include detailed and continuous nationwide surveys are required to identify unrecognized risk factors and to monitor the HEV infection prevalence in the Republic of Korea.

\section{Competing interests}

The authors declare that they have no competing interests.

\section{Authors' contributions}

YSY participated in ELISA experiment with HSY and HJL, interpretation of the data, and drafting of the manuscript. HSJ and HSY made substantial contributions to the conception and design of the study; acquisition, analysis, and interpretation of the data; and helped to draft the manuscript. CJL contributed to manage the fourth Korea National Health and Nutrition Examination Survey (KNHANES IV) for collection of serum samples. YSH and BHP participated in statistical analysis and interpretation of the data.

SWL and JYH conceived of the study, participated in its design and critical revision of the manuscript for important intellectual content. All authors read and approved the final manuscript.

\section{Acknowledgements}

We appreciate the financial support provided by the Korean National Institute of Health (KCDC Grant No. 4800-4851-306). We also thank individuals at the Neodin Medical Institute for their biostatistical advice and Dr. Dong-Hun Lee (Konkuk university, Seoul, Korea) for reviewing the manuscript.

\section{Author details}

'Division of Vaccine Research, Korea National Institute of Health, Korea Centers for Disease Control and Prevention, Osong-eup, CheongJu, Chungcheongbuk-do 363-951, Republic of Korea. ${ }^{2}$ Neodin Medical Institute, Seongdong-gu, Seoul 133-170, Republic of Korea. ${ }^{3}$ Division of Infectious Diseases Control, Korea Centers for Disease Control and Prevention, Osong-eup, CheongJu, Chungcheongbuk-do 363-951, Republic of Korea. ${ }^{4}$ Current affiliation: Division of Biosafety Evaluation and Control, Korea National Institute of Health, Korea Centers for Disease Control and Prevention, Osong-eup, CheongJu, Chungcheongbuk-do 363-951, Republic of Korea. ${ }^{5}$ Current affiliation: Division of General Affairs, Korea Centers for Disease Control and Prevention, Osong-eup, CheongJu,

Chungcheongbuk-do 363-951, Republic of Korea.

Received: 1 May 2014 Accepted: 18 September 2014

Published: 24 September 2014

\section{References}

1. Reyes GR, Purdy MA, Kim JP, Luk KC, Young LM, Fry KE, Bradley DW: Isolation of a CDNA from the virus responsible for enterically transmitted non-A, non-B hepatitis. Science 1990, 247:1335-1339.

2. Dalton HR, Bendall $R$, ljaz S, Banks M: Hepatitis E: an emerging infection in developed countries. Lancet Infect Dis 2008, 8:698-709.

3. Kumar A, Beniwal M, Kar P, Sharma JB, Murthy NS: Hepatitis E in pregnancy. Int J Gynaecol Obstet 2004, 85:240-244.

4. Verhoef L, Koopmans M, Duizer E, Bakker J, Reimerink J, Van Pelt W: Seroprevalence of hepatitis $\mathrm{E}$ antibodies and risk profile of HEV seropositivity in The Netherlands, 2006-2007. Epidemiol Infect 2012, 140:1838-1847.

5. Jeong SH: Current status of hepatitis e virus infection in Korea. Gut Liver 2011, 5:427-431.

6. ljaz S, Arnold E, Banks M, Bendall RP, Cramp ME, Cunningham R, Dalton HR, Harrison TJ, Hill SF, Macfarlane L, Meigh RE, Shafi S, Sheppard MJ, Smithson J, Wilson MP, Teo CG: Non-travel-associated hepatitis E in England and Wales: demographic, clinical, and molecular epidemiological characteristics. J Infect Dis 2005, 192:1166-1172.

7. Meng XJ, Wiseman B, Elvinger F, Guenette DK, Toth TE, Engle RE, Emerson $\mathrm{SU}$, Purcell RH: Prevalence of antibodies to hepatitis $E$ virus in veterinarians working with swine and in normal blood donors in the United States and other countries. J Clin Microbiol 2002, 40:117-122.

8. Kuniholm MH, Purcell RH, McQuillan GM, Engle RE, Wasley A, Nelson KE: Epidemiology of hepatitis E virus in the United States: results from the Third National Health and Nutrition Examination Survey, 1988-1994. J Infect Dis 2009, 200:48-56.

9. Kim YM, Jeong SH, Kim JY, Song JC, Lee JH, Kim JW, Yun H, Kim JS: The first case of genotype 4 hepatitis E related to wild boar in South Korea. J Clin Virol 2011, 50:253-256.

10. Takeda H, Matsubayashi K, Sakata H, Sato S, Kato T, Hino S, Tadokoro K, Ikeda $\mathrm{H}$ : A nationwide survey for prevalence of hepatitis $E$ virus antibody in qualified blood donors in Japan. Vox Sang 2010, 99:307-313.

11. Yun H, Lee H, Cheon D, Chu C, Oh KW, Kim YT, Jee Y: Seroprevalence of Hepatitis A and E Viruses Based on the Third Korea National Health and Nutrition Survey in Korea. Osong Public Health and Research Perspectives 2011, 2:46-50

12. Ahn JM, Kang SG, Lee DY, Shin SJ, Yoo HS: Identification of novel human hepatitis $E$ virus (HEV) isolates and determination of the seroprevalence of HEV in Korea. J Clin Microbiol 2005, 43:3042-3048. 
13. Chaussade H, Rigaud E, Allix A, Carpentier A, Touze A, Delzescaux D, Choutet P, Garcia-Bonnet N, Coursaget P: Hepatitis E virus seroprevalence and risk factors for individuals in working contact with animals. J Clin Virol 2013, 58:504-508.

14. Choi IS, Kwon HJ, Shin NR, Yoo HS: Identification of swine hepatitis E virus (HEV) and prevalence of anti-HEV antibodies in swine and human populations in Korea. J Clin Microbiol 2003, 41:3602-3608.

15. Song YJ, Jeong HJ, Kim YJ, Lee SW, Lee JB, Park SY, Song CS, Park HM, Choi IS: Analysis of complete genome sequences of swine hepatitis $E$ virus and possible risk factors for transmission of HEV to humans in Korea. J Med Virol 2010, 82:583-591.

16. Park HK, Jeong SH, Kim JW, Woo BH, Lee DH, Kim HY, Ahn S: Seroprevalence of anti-hepatitis E virus (HEV) in a Korean population: comparison of two commercial anti-HEV assays. BMC Infect Dis 2012, 12:142.

17. Yun H, Kim JS, Lee HJ, Jeong SH, Park SJ, Hwang SG, Kang SK, Jee Y, Kim JH: The complete genome sequence and molecular analysis of human hepatitis E virus genotype IV identified from a Korean patient. Arch Virol 2010, 155:1003-1008.

18. Kweon S, Kim Y, Jang MJ, Kim K, Choi S, Chun C, Khang YH, Oh K: Data resource profile: the Korea National Health and Nutrition Examination Survey (KNHANES). Int J Epidemiol 2014, 43:69-77.

19. Li RC, Ge SX, Li YP, Zheng YJ, Nong Y, Guo QS, Zhang J, Ng MH, Xia NS: Seroprevalence of hepatitis E virus infection, rural southern People's Republic of China. Emerg Infect Dis 2006, 12:1682-1688.

20. Lee S-D, Wang Y-J, Lu R-H, Chan C-Y, Lo K-J, Moeckli R: Seroprevalence of antibody to hepatitis $E$ virus among Chinese subjects in Taiwan. Hepatology 1994, 19:866-870.

21. Gessoni G, Manoni F: Hepatitis E virus infection in north-east Italy: serological study in the open population and groups at risk. J Viral Hepat 1996, 3:197-202.

22. Takahashi M, Tamura K, Hoshino Y, Nagashima S, Yazaki Y, Mizuo H, Iwamoto S, Okayama M, Nakamura Y, Kajii E, Okamoto H: A nationwide survey of hepatitis $\mathrm{E}$ virus infection in the general population of Japan. $J$ Med Virol 2010, 82:271-281.

23. Fogeda M, Avellon A, Echevarria JM: Prevalence of specific antibody to hepatitis $E$ virus in the general population of the community of Madrid, Spain. J Med Virol 2012, 84:71-74.

24. Echevarria JM: Light and darkness: prevalence of hepatitis e virus infection among the general population. Scientifica (Cairo) 2014, 2014:481016.

25. Bendall $R$, Ellis $V$, ljaz $S$, Ali $R$, Dalton $H$ : A comparison of two commercially available anti-HEV IgG kits and a re-evaluation of anti-HEV IgG seroprevalence data in developed countries. J Med Virol 2010, 82:799-805.

26. Lewis HC, Wichmann O, Duizer E: Transmission routes and risk factors for autochthonous hepatitis E virus infection in Europe: a systematic review. Epidemiol Infect 2010, 138:145-166.

27. Buti M, Clemente-Casares P, Jardi R, Formiga-Cruz M, Schaper M, Valdes A, Rodriguez-Frias F, Esteban R, Girones R: Sporadic cases of acute autochthonous hepatitis E in Spain. J Hepatol 2004, 41:126-131.

28. Dalton HR, Thurairajah PH, Fellows HJ, Hussaini HS, Mitchell J, Bendall R, Banks M, ljaz S, Teo CG, Levine DF: Autochthonous hepatitis E in southwest England. J Viral Hepat 2007, 14:304-309.

29. Okamoto $H$, Takahashi $M$, Nishizawa $T$ : Features of hepatitis $E$ virus infection in Japan. Intern Med 2003, 42:1065-1071.

30. Faber MS, Wenzel JJ, Jilg W, Thamm M, Hohle M, Stark K: Hepatitis E virus seroprevalence among adults, Germany. Emerg Infect Dis 2012, 18:1654-1657.

31. Eick A, Ticehurst J, Tobler S, Nevin R, Lindler L, Hu Z, Maclntosh V, Jarman R, Gibbons R, Myint K, Gaydos J: Hepatitis E seroprevalence and seroconversion among US military service members deployed to Afghanistan. J Infect Dis 2010, 202:1302-1308.

32. Ataei B, Nokhodian Z, Javadi AA, Kassaian N, Shoaei P, Farajzadegan Z, Adibi P: Hepatitis E virus in Isfahan Province: a population-based study. Int J Infect Dis 2009, 13:67-71.

33. Renou C, Moreau X, Pariente A, Cadranel JF, Maringe E, Morin T, Causse X, Payen JL, Izopet J, Nicand E, Boruliere M, Penaranda G, Hardwigsen J, Gerolami R, Peron JM, Pavio N: A national survey of acute hepatitis $E$ in France. Aliment Pharmacol Ther 2008, 27:1086-1093.
34. Koizumi Y, Isoda N, Sato Y, Iwaki T, Ono K, Ido K, Sugano K, Takahashi M, Nishizawa T, Okamoto $\mathrm{H}$ : Infection of a Japanese patient by genotype 4 hepatitis e virus while traveling in Vietnam. J Clin Microbiol 2004, 42:3883-3885.

35. Yuko K, Norio I, Yukihiro S, Takaaki I, Kazunori O, Kenichi I, Kentaro S, Masaharu T, Tsutomu N, Okamoto H: Infection of a Japanese Patient by Genotype 4 Hepatitis E Virus while traveling in Vietnam. J Clin Microbiol 2004, 42:8:3883-3885.

doi:10.1186/1471-2334-14-517

Cite this article as: Yoon et al:: Hepatitis E Virus (HEV) Seroprevalence in the general population of the Republic of Korea in 2007-2009: a nationwide cross-sectional study. BMC Infectious Diseases 2014 14:517.

\section{Submit your next manuscript to BioMed Central and take full advantage of:}

- Convenient online submission

- Thorough peer review

- No space constraints or color figure charges

- Immediate publication on acceptance

- Inclusion in PubMed, CAS, Scopus and Google Scholar

- Research which is freely available for redistribution 